\section{Discussion}

The term complete or D transposition of the great arteries is generally used to indicate the presence of normal or concordant atrioventricular connections with abnormal (transposed) ventriculoarterial connections. In the absence of additional communication between the systemic and pulmonary circulation about $80 \%$ of patients die before the age of six months..$^{1-3}$ In the presence of a large ventricular septal defect $70 \%$ die within the first six months and about $20 \%$ survive to one year. ${ }^{3}$ Pulmonary vascular disease is more common and occurs earlier (before the age of 1 year) in the presence of a ventricular septal defect. ${ }^{6-8}$ In patients with an intact ventricular septum the use of atrial septostomy followed by inflow "correction" using the Mustard operation $^{9}$ has significantly altered the natural history of the disease, with good early results, in several series. ${ }^{10-13}$ The Mustard operation is not totally corrective, however, and there is some concern about the long-term results. As the right ventricle continues to support the systemic circulation and tricuspid regurgitation, ${ }^{14}$ obstruction of systemic and pulmonary venous drainage ${ }^{1516}$ and late arrhythmias ${ }^{17}$ may constitute serious complications.

Total correction of transposition of the great arteries can be accomplished by transecting the aorta and pulmonary artery and reattaching them to the appropriate ventricles. One of the difficulties in applying this technique is the necessity of transposing the coronary ostia, which are very closely related to the aortic valve. The technique described in this paper illustrates the feasibility of this procedure very early in life. Another important consideration for the success of this operation is the state of the left ventricle, which should be capable of supporting the systemic circulation immediately after operation. In patients with transposition of the great arteries and intact ventricular septum the relatively low pulmonary vascular resistance results in diminution in left ventricular mass, ${ }^{18}$ which renders it incapable of supporting the circulation after total anatomical correction. This occurs shortly after birth concomittantly with the fall in pulmonary vascular resistance. ${ }^{19} 20$

The technique described in this paper was developed by us in 1972 and initially performed in three children with transposition of the great arteries and intact ventricular septae aged 3 weeks to 3 months. These children developed fatal acute left ventricular failure within hours of operation. For this reason we believe that to be successful the totally corrective procedure in transposition with intact ventricular septum must be performed very early in life. In contrast, the functional state of the left ventricle is maintained in patients with transposition of the great arteries and ventricular septal defect. Nevertheless, the corrective procedure must be applied before the onset of irreversible pulmonary vascular disease, which is thought to occur between the ages of 6 months and 1 year in most cases. Banding of the pulmonary artery might prevent the occurrence of severe pulmonary vascular disease as in case 2 . The creation of pulmonary stenosis in patients with transposition and ventricular septal defect, however, is not a guarantee against the development of pulmonary vascular disease. ${ }^{6}$

In the two patients described here total correction of transposition of the great arteries and ventricular septal defect resulted in an immediate fall of the pulmonary arterial pressure and was followed by dramatic improvement in their clinical states. We believe that this operation has an important role to play in the management of transposition of the great arteries.

\section{References}

${ }^{1}$ Fontana, R S, and Edwards, J E, Congenital Cardiac Disease. Philadelphia, Saunders, 1962.

2 Carlgren, L E, British Heart fournal, 1959, 22, 40.

${ }^{3}$ Liebman, J, Cullum, L, and Belloc, N B, Circulation, 1969, 40, 237.

4 Boessen, I, Circulation, 1963, 28, 885.

5 Hoffheinz, H J, Glaser, E, and Rodewald, G, Zentralbatt für Chirurgie, $1964,89,326$.

6 Viles, P H, Ongley, P A, and Titus, J L, Circulation, 1969, 40, 31.

7 Wagenvoort, C A, et al, Circulation, 1968, 38, 746.

${ }^{8}$ Newfeld, E A, Muster, A J, and Paul, M, Circulation, 1972, 46, suppl 2, p 97.

${ }^{9}$ Mustard, W T, et al, fournal of Thoracic and Cardiovascular Surgery, $1964,48,953$

10 Aberdeen, E, British Heart fournal, 1971, 33, 66.

11 Bonham Carter, R E, British Heart fournal, 1973, 35, 573.

12 Breckenridge, I M, et al, Lancet, 1972, 1, 1140.

13 Waldhausen, J A, et al, Circulation, 1971, 43, 738.

14 Tynan, M, Aberdeen, E, and Stark, J, Circulation, 1972, 45, suppl 1, p 3

15 Stark, J, et al, Circulation, 1972, 45/46, suppl 1, p 116.

16 Mazzei, E A, Mulder, D G, Annals of Thoracic Surgery, 1971, 11, 243.

${ }^{17}$ El-Said, G, et al, American fournal of Cardiology, 1972, 30, 526.

${ }_{18} \mathrm{Lev}, \mathrm{M}$, et al, American fournal of Cardiology, 1969, 23, 409.

19 Tynan, M, Circulation, 1972, 46, 809.

${ }^{20}$ Newfeld, E A, et al, American fournal of Cardiology, 1974, 34, 75.

\title{
Dual-demand pacing for reciprocating atrioventricular tachycardia
}

\author{
DENNIS KRIKLER， PAUL CURRY， JACQUES BUFFET
}

British Medical fournal, 1976, 1, 1114-1116

\section{Summary}

By using programmed electrical stimulation of the heart and studying the initiation and termination of reciprocating atrioventricular tachycardia two patients with the

\footnotetext{
Cardiovascular Division, Royal Postgraduate Medical School, London W12 0HS

DENNIS KRIKLER, MD, FRCP, consultant cardiologist

PAUL CURRY, MB, MRCP, research fellow

Department of Biomedical Development, L'Electronique Appliquée, 92120 Montrouge, France

JACQUES BUFFET, director of research
}

Wolff-Parkinson-White syndrome were shown to respond
rapidly and consistently to fixed-rate pacing. A demand
pacemaker was implanted in each patient, having been
modified so as to switch into the fixed-rate mode when-
ever the tachycardia began, thereby terminating the
arrhythmia. This appears to be a promising form of
treatment in patients with otherwise intractable
paroxysmal tachycardia who have been shown by careful
study to respond in this way.

While few patients with cardiac arrhythmias need therapeutic pacing, it may occasionally be the only means of controlling intractable paroxysmal tachycardia. In reciprocating tachycardias involving either the atrioventricular node or an anomalous 
bypass or both electrophysiological studies have shown that they may be both initiated and stopped by suitably timed premature beats induced by intracardiac stimulation close to the latent or preformed circuit. ${ }^{1}$ For therapeutic use special external units ${ }^{2} 3$ or the activation of implanted units by an external device or magnet ${ }^{4-6}$ are required. We have found that a conventional demand pacemaker modified to respond to tachycardia by switching into the fixed-rate mode automatically is practicable and report two cases in which it proved successful in promptly terminating attacks of paroxysmal tachycardia complicating the Wolff-Parkinson-White syndrome.

\section{Case 1}

A 64-year-old woman suffered from reciprocating atrioventricular tachycardia due to the Wolff-Parkinson-White syndrome type A complicated by left bundle-branch block. She was referred because of an increase in frequency of the attacks during the preceding three years. Their onset and termination were of ten accompanied by syncope. During tachycardia the QRS complexes on the electrocardiogram (ECG) showed left bundle-branch block. Termination of the tachycardia by whatever means was followed by grossly delayed recovery of sinoatrial nodal activity with junctional escape beats that showed left bundle-branch block (fig 1). Various antiarrhythmic agents, including digoxin, quinidine, and beta-adrenergic blocking agents, failed to prevent the attacks. Electrophysiological studies confirmed the presence of a left-sided paraseptal anomalous tract, left bundlebranch block, and sinoatrial block. ${ }^{7}$ They also showed that single premature beats electrically induced in the right ventricle over much of the cardiac cycle terminated induced tachycardias. Fixed-rate right ventricular pacing at 70 beats $/ \mathrm{min}$ stopped induced attacks within 30 seconds.

A standard demand pacemaker (ELA Stanium) was modified to pace at a fixed 70 beats/min whenever the heart rate exceeded 150 beats/ min or dropped below 70 beats/min and was implanted (June 1974) with an epicardial electrode positioned in the right ventricle corresponding to the point where endocardial stimulation had been most successful. Over the next 18 months the patient was aware of only two episodes of tachycardia. The first stopped spontaneously after 30 seconds; the second occurred after she had fallen on to her chest and took two hours to resolve. In case she had damaged the electrode the original mercury-powered unit was replaced by a lithiumiodide-powered ELA Stimulith pacemaker with response characteristics identical with those of the first unit, and there were no further

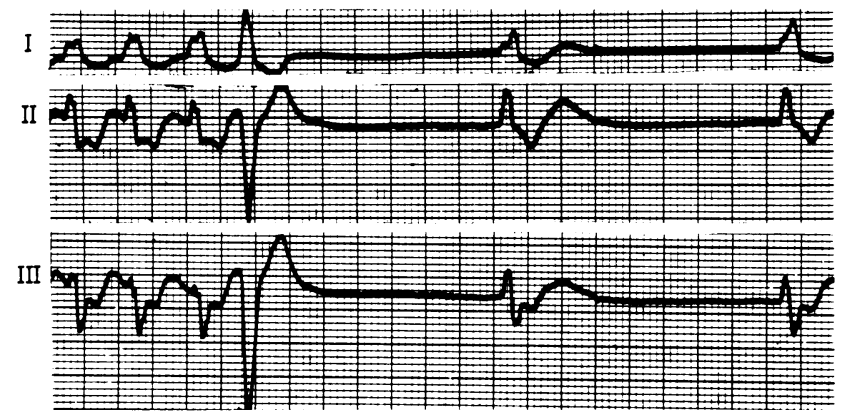

FIG 1-Case 1. ECG showing spontaneous termination of reciprocating atrioventricular tachycardia by ventricular extrasystole. Next two beats are junctional in origin and, like the tachycardia, show pattern of left bundlebranch block.

V6

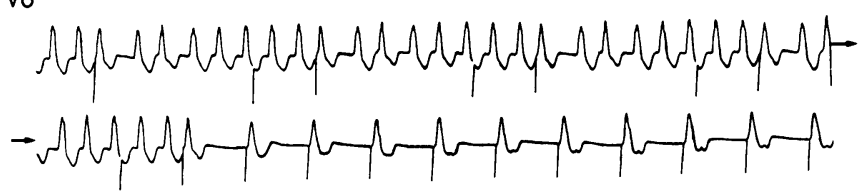

FIG 2-Case 1. ECG showing reciprocating atrioventricular tachycardia with left bundle-branch block ( 165 beats $/ \mathrm{min}$ ) after automatic activation of pacemaker. Stimuli 1, 3, 5, and 7 show capture and temporary slowing of tachycardia to heart rates below that which would activate it; termination occurs with ninth stimulus. Unit continues to pace at 70 beats $/ \mathrm{min}$ because of inherent sinus bradycardia. problems. Fig 2 shows a typical termination of an induced attack; the interruption of pacing before termination reflects capture and transient slowing of the tachycardia with inhibition of the pacemaker for single beats. The unit continued to pace after termination of the tachycardia because of depressed sinoatrial nodal function, and at the time of writing it was operating most of the time, as she had developed persistent sinus bradycardia due to the sinoatrial nodal disease.

\section{Case 2}

A 44-year-old man had had recurrent attacks of paroxysmal supraventricular tachycardia for 15 years. Rarely atrial fibrillation with narrow QRS complexes was also seen. Intermittent pre-excitation was seen only once during sinus rhythm, but electrophysiological study confirmed the presence of a latent bypass affecting the left side of the heart-that is, conducting only retrogradely. ${ }^{8}$ During this study we could initiate and terminate reciprocating atrioventricular tachycardias with induced atrial and ventricular extrasystoles over a wide range of coupling intervals. An area in the coronary sinus close to the ostium was shown to be the most suitable for terminating tachycardia by producing block in the atrioventricular node.

Syncope had recently developed in some attacks, and the rate of the tachycardia was found to be 220 beats $/ \mathrm{min}$. The attacks occurred progressively more often, necessitating cardioversion and, more recently, intravenous verapamil. ${ }^{9}$ Prophylactic digitalis, quinidine, beta-blocking agents, and verapamil-singly and in appropriate combinations to the limit of tolerance-had been unsuccessful. Accordingly, an ELA Stimulith pacemaker designed to function in exactly the same way as in case 1 was inserted with an endocardial electrode positioned in the coronary sinus. To produce a greater delay within the atrioventricular node the patient was also given verapamil $80 \mathrm{mg} /$ three times a day, and the attacks of tachycardia were consistently terminated within 30 seconds whenever they occurred (fig 3). This was corroborated by several tests in which induced atrial extrasystoles led to tachycardia with termination within six beats.
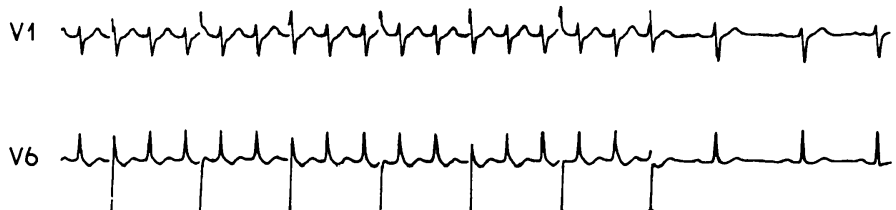

FIG. 3-Case 2. ECG showing automatic firing of pacemaker at 72 beats/min in response to tachycardia $(185$ beats $/ \mathrm{min})$. Seventh stimulus activates left atrium from coronary sinus at critical prematurity, causing block of conduction within atrioventricular node, disruption of re-entry circuit, and restoration of sinus rhythm.

\section{Discussion}

Since reciprocating tachycardias may be terminated by suitably timed, electrically induced premature beats produced in close proximity to the circuit, it is theoretically possible that a suitably designed pacemaker could be used when medical measures fail. Conventional antiarrhythmic agents produce a satisfactory response in most patients with such tachycardias, usually by suppressing the extrasystoles that initiate tachycardia rather than by preventing them from getting into the circuit. It is sometimes impossible to prevent the extrasystoles, and occasionally other mechanisms may be responsible for the initiation of tachycardia-for example, junctional escape beats in the presence of sinoatrial disease. ${ }^{1011}$ Furthermore, antiarrhythmic agents that normally control tachycardias may increase the tendency for them to occur in patients with sinoatrial disease by depressing the sinoatrial node even further, thus enabling subsidiary foci or circuits to function. Here pacemakers may be useful in maintaining a physiologically desirable heart rate, thus preventing syncope due to bradycardia, as well as in suppressing potentially dangerous escape rhythms.

Several ingenious antiarrhythmic pacemakers have been described, including scanning pacemakers ${ }^{3}$ (which automatically change the coupling interval of the induced extrasystole); a 
high-frequency stimulator that blankets the re-entry zone, and thereby fortuitously induces a suitably timed extrasystole $;^{3}$ and the variable-hysteresis orthorhythmic pacemaker." These are all experimental, and implantable units are not available. Fixedrate pacing, however, is known to be of value in some cases, and this may be achieved either by using a demand pacemaker with a magnetic reed switch activated by an external magnet ${ }^{4}$ or by holding an external induction-coil ${ }^{5}$ or radio-frequency pacemaker $^{6}$ over the site of an implanted receiver. These latter methods, however, need the active intervention of the patient. If tachycardia is associated with syncope, or if serious attacks occur during sleep, the patient may be at considerable risk before the pacemaker can be activated. Here the dual-demand pacemaker may help. By automatically switching from the demand to the fixed-rate mode in response to the rate of the heart, units can be tailored to function at rates corresponding to the patient's tachycardia. Careful intracardiac electrophysiological studies ${ }^{12}$ will show whether the method is suitable for a particular patient. The unit can easily be tested at follow-up if competitive atrial pacing is induced by an external magnet applied over the generator, which will initiate an attack after a variable period. If the magnet is then removed the unit can be seen to function and terminate the attack.

Both of our patients had pre-excitation, and such units may well have their greatest application in this field. When the bypass is left-sided, stimulation from the coronary sinus ${ }^{13}$ offers the facility to influence both the nodal and extranodal limbs of the tachycardia circuit and may thus increase the chance of terminating re-entry. We have studied several other patients who were satisfactorily controlled by antiarrhythmic drugs in whom dual-demand pacemaking was tested successfully. For selected cases the dual-demand pacemaker offers an automatic unit that can be pretested and that works in response to the patient's own tachycardia, switching itself off after the tachycardia has been controlled unless bradycardia (perhaps due to sinoatrial disease) persists, when it acts to prevent both syncope and further recurrences.

This work was supported by a grant from the British Heart Foundation. We are grateful to Dr Philippe Coumel, who helped with the investigation of case 1 , for advice in the development of the pacemaker, and to Dr Celia Oakley, who kindly referred the patients.

\section{References}

1 Wellens, H J J, Electrical Stimulation of the Heart in the Study and Treatment of Arrhythmias, Leiden, Stenfert Kroese, 1971.

Guize, L, Zacouto, F, and Lenégre, J, Presse Médicale, 1971, 79, 2071.

${ }^{3}$ Spurrell, R A J, in Cardiac Arrhythmias, the Modern Electrophysiological Approach, ed. D M Krikler and J F Goodwin, p 238. London, Saunders, 1975.

${ }^{4}$ Ryan, G F, et al, Circulation, 1968, 38, 1037.

Dreifus, L S, et al, American fournal of Cardiology, 1971, 28, 586.

Williams, D O, and Davison, P H, British Heart fournal, 1974, 36, 336 Krikler, D, et al. Submitted for publication.

${ }^{-}$Krikler, D M, in Cardiac Arrhythmias, the Modern Electrophysiological Approach, ed D M Krikler and J F Goodwin, p 144. London, Saunders, 1975.

${ }^{9}$ Krikler, D M, and Spurrell, R A J, Postgraduate Medical fournal, 1974, 50, 447.

${ }^{10}$ Harper, R, et al, European fournal of Cardiology, 1974, 2, 207.

11 Coumel, $\mathrm{Ph}$, et al, British Heart fournal. In press.

12 Curry, P V L, in Cardiac Arrhythmias, the Modern Electrophysiological Approach, ed D M Krikler and J F Goodwin, p 39. London, Saunders, 1975.

${ }^{13}$ Kramer, D H, and Moss, A J, Circulation, 1970, 42, 427.

\title{
A controlled comparison of flupenthixol and amitriptyline in depressed outpatients
}

\author{
J P R YOUNG, W C HUGHES, M H LADER
}

British Medical fournal, 1976, 1, 1116-1118

\section{Summary}

Sixty depressed outpatients were allocated to treatment with either amitriptyline (75-225 $\mathrm{mg} /$ day) or flupenthixol $(1.5-4.5 \mathrm{mg} /$ day) in flexible dosage for six weeks under double-blind procedures. Various objective and subjective assessments were carried out before and after one, three, and six weeks of treatment. Twenty-three patients completed the course of amitriptyline and 28 the course of flupenthixol. Almost all variables improved significantly over time, irrespective of drug. On most ratings there were no significant differences between the two drugs, but the trends favoured flupenthixol. In particular, flupenthixol lessened anxiety scores more than amitriptyline. Unwanted effects were few and not trouble-

St Thomas's Hospital, London SE1

J P R YOUNG, MD, MRCP, consultant in psychological medicine W C HUGHES, MB, BS, senior registrar in psychological medicine

Institute of Psychiatry, University of London, London SE5 M H LADER, MD, PHD, reader in clinical psychopharmacology some except in two patients receiving amitriptyline. Flupenthixol, in low dosage, is a useful alternative antidepressant for depressed outpatients.

\section{Introduction}

The thioxanthene derivative flupenthixol is of established value in the treatment of schizophrenia. ${ }^{1}$ After some early reports, ${ }^{2}{ }^{3}$ Reiter $^{4}$ described his uncontrolled impression of the antidepressant effect of flupenthixol in low doses in an extensive outpatient series. The recovery rate was over $60 \%$, and he claimed that flupenthixol was quick acting, effective in low doses, and without significant unwanted effects. Merskey ${ }^{5}$ noted a "worth-while sustained improvement" in 24 out of 53 patients with affective disorders. In 12 patients the depression was endogenous; in most the illness was chronic, and many patients had not responded to treatment with tricyclic compounds, monoamine oxidase inhibitors, or electric convulsion therapy (ECT). Others have noted flupenthixol's antidepressant properties, ${ }^{6-8}$ and Frolund ${ }^{9}$ found the drug effective in a trial with 231 patients suffering from anxiety and depression. Flupenthixol was given for only two weeks, however, and the drop out rate was high. Treatment was again given for only two weeks in a double-blind comparative trial which showed flupenthixol to be more effective than nortriptyline in the 